\title{
A NEW ELECTROCHEMICAL SENSOR BASED ON MODIFIED CARBON NANOTUBE-GRAPHITE MIXTURE PASTE ELECTRODE FOR VOLTAMMETRIC DETERMINATION OF RESORCINOL
}

\author{
MANJUNATHA JG* \\ Department of Chemistry, FMKMC College (Mangalore University Constituent College), Madikeri, Karnataka, India. \\ Email: manju1853@gmail.com
}

Received: 29 June 2016, Revised and Accepted: 08 September 2017

\section{ABSTRACT}

Objective: A new carbon nanotube (CNT)-graphite mixture paste electrode modified by Sodium dodecyl sulfate (SDS) surfactant (SDSMCNTGMPE) was prepared and applied for sensitive electrochemical determination of resorcinol (RS).

Method: Cyclic voltammetry, variable pressure scanning electron microscopy, and differential voltammetry were employed for the surface analysis of the bare CNT-graphite mixture paste electrode and SDSMCNTGMPE. Comparison between the unmodified electrode and modified electrode, the modified electrode oxidation peak current significantly improved. The effects of the pH, scan rate, and concentration of RS on the peak current were investigated.

Results: Results indicated that the peak current of RS is highest in $0.2 \mathrm{M} \mathrm{pH} 7.0$ phosphate buffer solutions and that the electrode reaction corresponds to a rate controlled process. Under optimized experimental conditions, the oxidation peak current of RS was linear over a concentration range of $2 \times 10^{-6}$ to $1.0 \times 10^{-3} \mathrm{M}$ with a detection limit of $5.8 \times 10^{-6} \mathrm{M}$ and quantification limit of $19 \times 10^{-6} \mathrm{M}$.

Conclusion: The prepared sensor also shows other features such as good stability, reproducibility and repeatability. The proposed sensor exhibits good application toward the detection of RS in commercial RS lotion samples.

Keywords: Resorcinol, Carbon nanotube-graphite mixture paste electrode, Sodium dodecyl sulfate.

(C) 2017 The Authors. Published by Innovare Academic Sciences Pvt Ltd. This is an open access article under the CC BY license (http://creativecommons. org/licenses/by/4. 0/) DOI: http://dx.doi.org/10.22159/ajpcr.2017.v10i12.21028

\section{INTRODUCTION}

Resorcinol (RS) is used to treat some diseases such as acne, seborrheic dermatitis, eczema, psoriasis, and other skin illness. RS also used to remove unwanted skin. RS is an m-dihydroxybenzene. Benzene is one of the molecules to increase the risk of cancer and other disorders. Benzene contains a harmful things and low degradability in nature, they are considered as environmental pollutants [1,2]. Therefore, it is needed to prepare a simple and fastest analytical method for the detection and determination of RS. Many people proposed many analytical methods to determine RS such as electrochemical $[3,4]$, flow injection chemiluminescence [5], High-performance liquid chromatography [6], fluorescence [7], surface plasmon resonance [8], and spectrophotometric [9]. The redox mechanism of RS was shown in Scheme 1 [4].

Electrochemical detection is a best substitute for the detection of many compounds in pharmaceutical and biological samples [10-15]. However, the detection is sometimes suppressed because it presents limitations of selectivity due to the obstruction from the species which are electroactive at same potentials to the analyte of interest [16]. In these circumstances, a many types of carbon materials such as

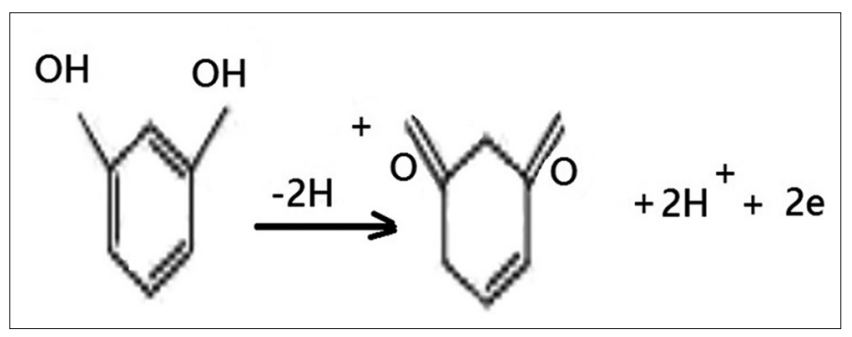

Scheme 1: The scheme of oxidation of resorcinol $-2 \mathrm{H}^{+}$ carbon nanotubes (CNT) and graphite carbon electrodes have been investigated in electroanalysis to get good results in sensitivity, selectivity, and stability of the electrode. The development of sensitive and selective voltammetric sensors has become widely popular, due in part to their simplicity, rapidity, precision, and availability of the basic equipment in laboratory and field uses. The electrocatalytic property of electrode usually relies on the electron transfer at the electrode/ electrolyte interface, surface area, and electrical conductivity of the electrode material. Carbon-based materials such as CNT and graphite having large surface area [17], speedy electron transfer, and very good electrical conductivity $[18,19]$ have great use in chemical, biological sensors $[10,14,16,20]$, fuel cell [21], and supercapacitors [22]. However, graphite suffers restrictions due to restacking which can be obviated by combine functional groups such as oxygen, nitrogen [23], and preparing hybrid materials with other nanomaterials such as CNT [24], metal [25], and metal oxides [26]. The common strategies followed to obtain graphite /CNT hybrid material are through simple mixing in mortar with silicone oil [27].

Surfactants have been used extensively in the field of electroanalytical chemistry for many works. Surfactants have been utilized in electrochemistry to enhance the property of the electrode solution interface [10] and also enhance the detection limits of some molecules. The fast literature showed that the electrochemical effect of these compounds was increased in the presence of trace surfactants [11,28-31].

In this work, the electrochemical behavior of RS was analyzed at Sodium dodecyl sulfate (SDS) SDSMCNTGMPE. The reaction mechanisms of RS molecule were examined by cyclic voltammetry (CV) and differential voltammetry (DPV) with different parameters like varying scan rates at different $\mathrm{pH}$ values in phosphate buffer solutions (PBS). Carbon electrodes are having tendency to surface fouling problem, the rate and 
extent of passivation of SDSMCNTGMPE were examined by scanning several continuous cycles with $\mathrm{CV}$ and analyzing the surface by variable pressure scanning electron microscopy (VPSEM). The results were compared to the oxidation of these compounds at carbon electrodes. To the best of our scientific knowledge, there is no voltammetric sensor based on modified CNT-graphite mixture paste electrode for voltammetric determination of RS.

\section{EXPERIMENTAL}

\section{Reagents}

Silicone oil and SDS were purchased from Nice Chemicals, India. RS purchased from Himedia, India. RS was prepared $25 \times 10^{-3} \mathrm{M}$ stock solution by dissolving in double distilled water. Other chemicals were of analytical grade and used without further purification. SDS was prepared $25 \times 10^{-3} \mathrm{M}$ stock solutions by dissolving in double distilled water. An entire analysis, the supporting electrolyte used was $\mathrm{pH} 7$ (0.2 M PBS). Spectroscopically, pure multiwall CNTs were obtained from Sigma-Aldrich India.

\section{Apparatus}

Electrochemical analysis (EA) was carried out with a model-201 (EA-201 Chemilink system, Mumbai, India) in a normal three-electrode system. The working electrode was a SDSMCNTGMPE and bare CNT-graphite mixture paste electrode (BCNTGMPE), having cavity of $3 \mathrm{~mm}$ diameter. The counter electrode was a bright platinum wire with saturated calomel electrode as reference electrode completing the circuit.

\section{Preparation of the electrochemical sensor electrodes}

The BCNTGMPE was prepared by mixing in a mortar CNT, graphite, and silicone oil in ratio $35.0 \% \mathrm{w} / \mathrm{w}$ CNTs, $35.0 \% \mathrm{w} / \mathrm{w}$ graphite, and $30.0 \% \mathrm{w} / \mathrm{w}$ silicone oil. The paste was then packed into the cavity of a homemade electrode and smoothed out on a tissue paper. SDS modified carbon paste electrode (SDSMCNTGMPE) was prepared by immobilizing $20 \mu \mathrm{L}$ of SDS surfactant on the surface of the BCNTGMPE for $5 \min [10,11]$.

\section{Electrochemical measurements procedure}

Electrochemical depictions of the electrodes were performed in $0.2 \mathrm{M}$ phosphate buffer ( $\mathrm{pH}$ 7.0) through CV and DPV in the potential range from 0 to $100 \mathrm{mV}$ all electrochemical measurements were carried out at room temperature. RS stock solution was added as per the requirement. The electrochemical cell contained a SDSMCNTGMPE or BCNTGMPE as a working electrode, a Pt wire counter electrode, and $\mathrm{Ag} / \mathrm{AgCl}(3 \mathrm{M} \mathrm{KCl})$ reference electrode.

\section{RESULTS AND DISCUSSION}

\section{Surface analysis by VPSEM studies}

VPSEM is a powerful technology to offer a general view of the electrode surface. Compared the VPSEM images of BCNTGMPE (Fig. 1a) and SDSMCNTGMPE (Fig. 1b), the mixture of CNT, graphite, and silicone oil was clearly observed. When the SDS was electrodeposited on the electrode surface, the deposition of SDS with some large group of molecules on observed with VPSEM. This indicated that the SDS film was successfully fabricated.

\section{Stability and reproducibility}

The SDSMCNTGMPE sensor had a good stability and the peak current only decreased $<4 \%$ after the electrode for 25 days. Tested the reproducibility of the modified electrode, five SDSMCNTGMPE were prepared for the detection of RS. The relative standard deviation (RSD) of peak currents for $\mathrm{RS}(\mathrm{n}=5)$ was calculated as $4.67 \%$, values indicating that the reproducibility of the proposed electrode was good. The modified electrode shows good stability, reproducibility, and repeatability.

The electrochemical behavior of the SDSMCNTGMPE and BCNTGMPE toward potassium ferrocyanide

The electrochemical behavior of the SDSMCNTGMPE toward potassium ferrocyanide was also examined by CV. Fig. 2 shows cyclic
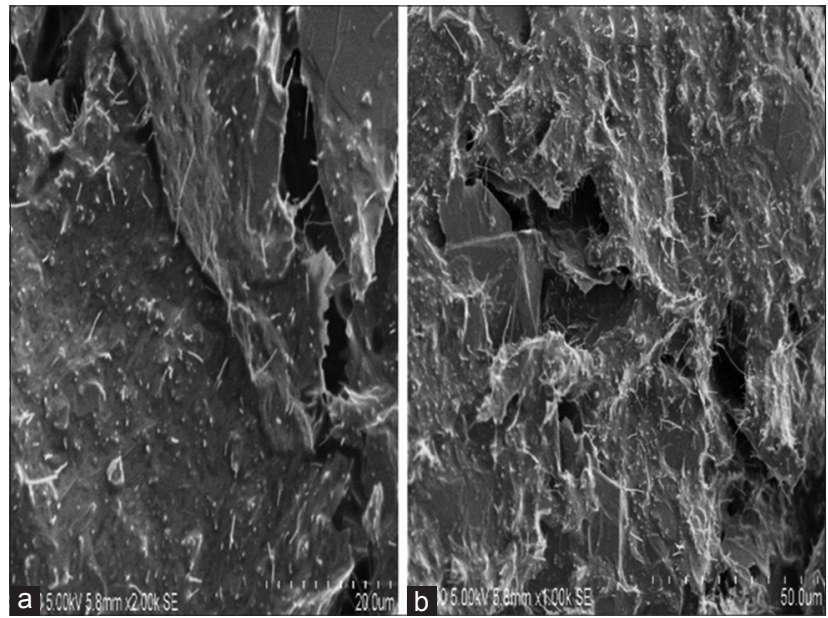

Fig. 1: Variable pressure scanning electron microscopy images of (a) the BCNTGMPE (b) SDSMCNTGMPE

voltammograms of BCNTGMPE and SDSMCNTGMPE, containing $1 \mathrm{M}$ $\mathrm{KCl}$ and $1 \mathrm{mM}$ potassium ferrocyanide. The SDSMCNTGMPE exhibited a characteristic increase of the peak for ferrocyanide represents the successful modification. Higher peak currents (Ipa $=26.6 \mu \mathrm{A}$, Ipc $=24 \mu \mathrm{A}$; $\Delta \mathrm{Ep}=40 \mathrm{mV}$ ) when compared with those at the BCNTGMPE (Ipa $=11.6 \mu \mathrm{A}$, Ipc=7.4 $\mu \mathrm{A} ; \Delta \mathrm{Ep}=128 \mathrm{mV}$ ) were found. This can be responsible to the higher electrochemical activity of surfactant which gives the increase of the active area of the electrode. The presence of the electrodeposited SDS surfactant impacts the slight shifts of the anodic peak potential to less positive side, giving rise to a smaller peak-to-peak separation $(\triangle \mathrm{Ep}=40 \mathrm{mV})$. This more than two-fold increase in both the anodic and cathodic peak currents can be attributed to the electrocatalytic effect of the surfactant.

\section{Electrochemistry of RS at SDSMCNTGMPE}

The voltammetric behavior of RS at SDSMCNTGMPE was investigated with CV. Fig. 3 shows the CVs at the SDSMCNTGMPE in $0.2 \mathrm{M}$ PBS at $\mathrm{pH} 7.0$ in the absence (blank) and presence of $1 \mathrm{mM}$ of RS at a scan rate of $100 \mathrm{mV} / \mathrm{s}$. The CVs on SDSMCNTGMPE with RS shows broader oxidation peak with the peak potential at $542 \mathrm{mV}$. For SDSMCNTGMPE absence RS, no significant peak appeared (solid line) and the current enhancement after the addition of RS is completely evident (dashed line). Above results show that the SDSMCNTGMPE improves the electrocatalytic activity for RS oxidation. In the present electrochemical approach, the electrode effect was directly proportional to the oxidation of the electroactive species produced.

\section{Electrochemical study of RS at SDSMCNTGMPE by CV and DPV} The electrochemical behavior of $1 \mathrm{mM}$ RS in $0.2 \mathrm{M}$ PBS (pH 7.0) at the BCNTGMPE and the SDSMCNTGMPE were studied by CV. As shown in Fig. 4, the CVs obtained at the BCNTGMPE display an irreversible oxidation peak with very small peak current $18.5 \mu \mathrm{A}$. In contrast, the CVs of RS at the SDSMCNTGMPE (dashed line) show well-defined peak in potential range between 0 and $100 \mathrm{mV}$, with the greatly enhanced peak current $50.5 \mu \mathrm{A}$. The appearance of the irreversible peak indicates that SDSMCNTGMPE film can significantly accelerate the oxidation reaction process. It is worth noting that the peak currents obtained at SDSMCNTGMPE present the higher values in comparison with those obtained at the BCNTGMPE, about 2.7 times as large as that recorded at SDSMCNTGMPE. The enhanced results show that SDSMCNTGMPE exhibit good conductivity and excellent catalytic activity toward the oxidation of RS.

Electrochemical determination of RS was performed by employing the DPV response at BCNTGMPE and SDSMCNTGMPE in 0.2 M PBS (pH 7.0) solution containing $1 \mathrm{mM}$ RS. As shown in Fig. 5, at the BCNTGMPE, the electrooxidation of RS presents very small peak current so that the determination of the RS at BCNTGMPE is very difficult. In contrast, at 


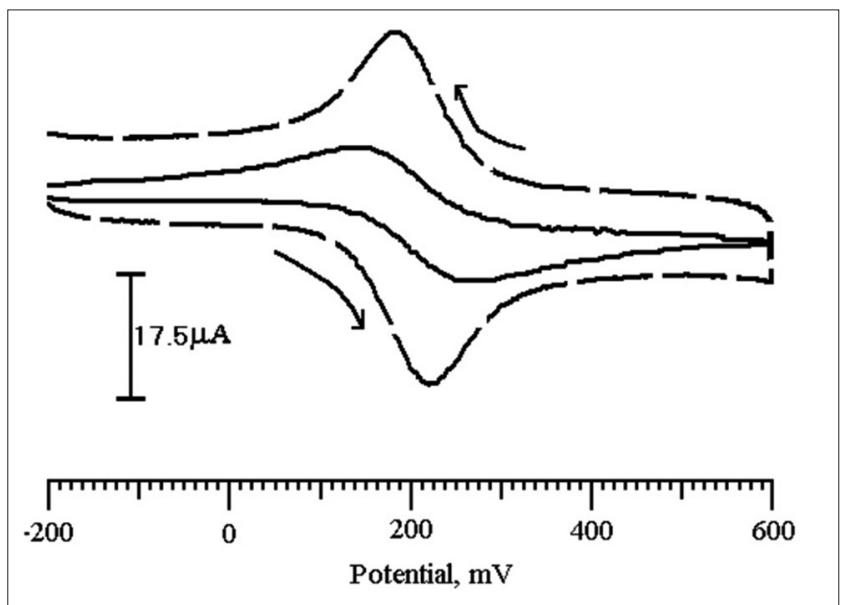

Fig. 2: Cyclic voltammograms of $1 \mathrm{mM}$ potassium ferrocyanide at the BCNTGMPE (solid line) and at the SDSMCNTGMPE (dashed line) in $1 \mathrm{M} \mathrm{KCl}$

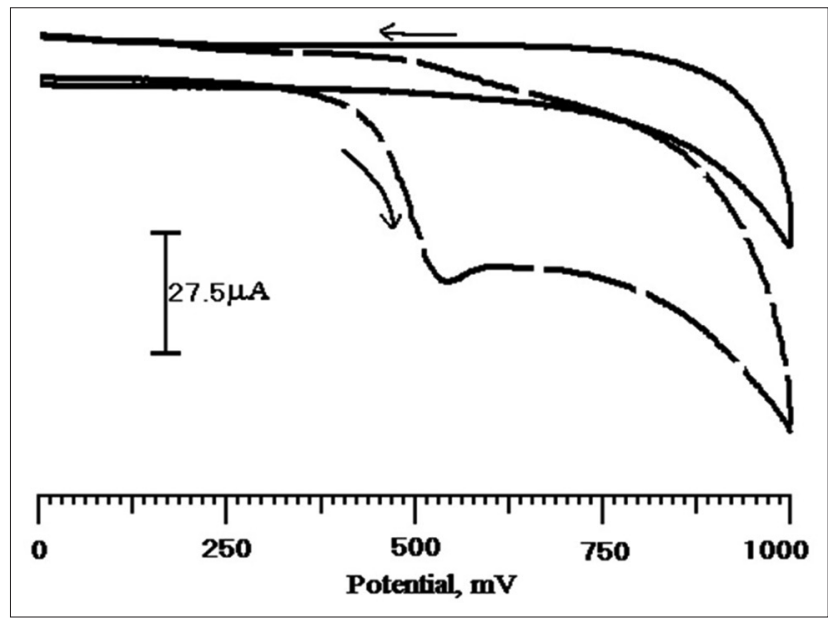

Fig. 3: A typical cyclic voltammograms of SDSMCNTGMPE with $1 \mathrm{mM}$ resorcinol (RS) in pH 7. Phosphate buffer solutions (PBSs) (dashed line) without $1 \mathrm{mM}$ RS at pH 7. PBS blank (solid line)

the SDSMCNTGMPE well-defined oxidation peak and peak current were observed at $544 \mathrm{mV}, 7.8 \mu \mathrm{A}$, respectively, with higher (approximately 2.6 times) oxidation peak current appeared.

\section{Effect of scan rate}

The effect of the scan rate on the electrochemical reactions of RS was studied by $\mathrm{CV}$ at the SDSMCNTGMPE. The results are exhibiting an increase in the redox peak currents with an increase in the scan rate $(100-500 \mathrm{mV} / \mathrm{s})$, as revealed in Fig. 6a. The peak currents versus scan rate $(v)$ are plotted in Fig. 6b. The graph displays a linear relationship between the scan rates and peak currents. In the scan rate from 100 to $500 \mathrm{mV} / \mathrm{s}$, the anodic peak currents usually proportional to the scan rate. The linear regression equation for the SDSMCNTGMPE is Ipa $(\mu \mathrm{A})$ $=36.97+0.1349 \mathrm{~V}\left(\mathrm{mV} / \mathrm{s}^{1}\right)$ with the correlation coefficient equal to 0.9907. The regression equation indicates the SDSMCNTGMPE reaction process was adsorption-controlled [32-34].

\section{Influence of $\mathbf{p H}$}

The influence of $\mathrm{pH}$ on the oxidation peak current of RS at the SDSMCNTGMPE was examined by recording CV in PBS (pH 5.5-8) shows in Fig. 7A. The study of the influence of $\mathrm{pH}$ on the anodic peak current was also introduced out to determine the $\mathrm{pH}$ value for the maximum evidence. The height of the peak reached a highest and the shape of the curve is good in PBS at pH 7.0 than other buffers shows

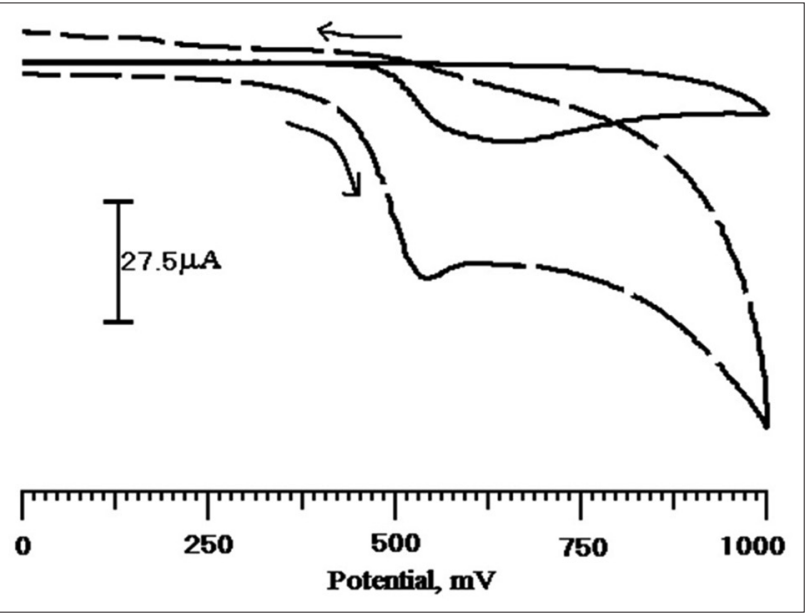

Fig. 4: Cyclic voltammograms of $1 \mathrm{mM}$ resorcinol in $\mathrm{pH} 7$ phosphate buffer solutions at the BCNTGMPE (solid line), the SDSMCNTGMPE (dashed line)

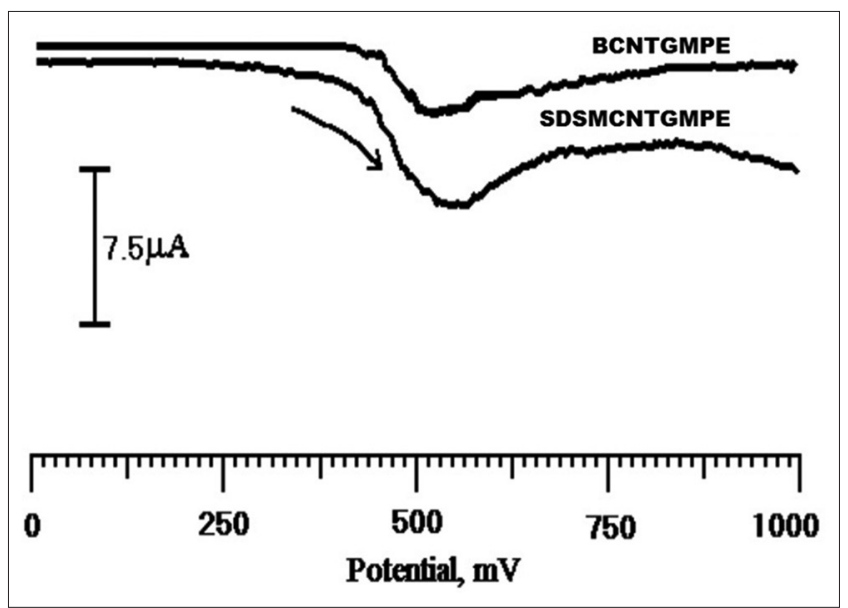

Fig. 5: DPVs of a solution containing $1 \mathrm{mM}$ resorcinol in $0.2 \mathrm{M}$ phosphate buffer solutions ( $\mathrm{pH} \mathrm{7}$ ) at the BCNTGMPE and SDSMCNTGMPE

Fig. 7B. This supporting electrolyte was chosen with respect to good peak for the detection of RS. The effect of $\mathrm{pH}$ on the anodic potential and anodic peak current was analyzed over a $\mathrm{pH}$ range 5.5-8 in the solution containing $1 \mathrm{~mm}$ RS using CV. The $\mathrm{E}^{\circ}$ of RS decreased with respect to increasing $\mathrm{pH}$. From the plot of Epa versus $\mathrm{pH}$, the slope of 0.094 was obtained, corresponding to the following equation: Epa $(\mathrm{mV})=1244.97$ $94.514 \mathrm{pH}\left(\mathrm{R}^{2}=0.998\right)$ shows in Fig. 7C.

\section{Calibration plot and detection limit}

The quantitative determination of RS at SDSMCNTGMPE is carried out by CV technique under the optimized conditions. CV was carried out in the potential range of 0 to $1000 \mathrm{mV}$ for the addition different concentrations of RS $(20-1000 \mu \mathrm{M})$ in $0.2 \mathrm{M}$, PBS (pH 7.0). Obviously, the anodic current of RS has been obtained nearly at the potential of $544 \mathrm{mV}$ increased as the concentration of RS increased, attributed to the electrooxidation of RS at the modified electrode. A calibration plot was made between the concentrations of RS and peak currents in Fig. 8. The linear range of RS concentration was from 20 to $1000 \mu \mathrm{M}$ and the regression equations were Ipa $(\mathrm{A})=7.6894 \times 10^{-6}+0.05424 \mathrm{C}$ $\left(\mathrm{R}^{2}=0.9937\right)$, the detection limit was $5.8 \times 10^{-6}$ and limit of quantification $19 \times 10^{-6}(\mathrm{~S} / \mathrm{N}=3)$. The result was compared with other literature $[3,4,35,36]$ (Table 1). The proposed electrode shows good comparable electroanalytical values with the previous reports revealing the ability of the SDSMCNTGMPE toward sensitive determination of RS. 


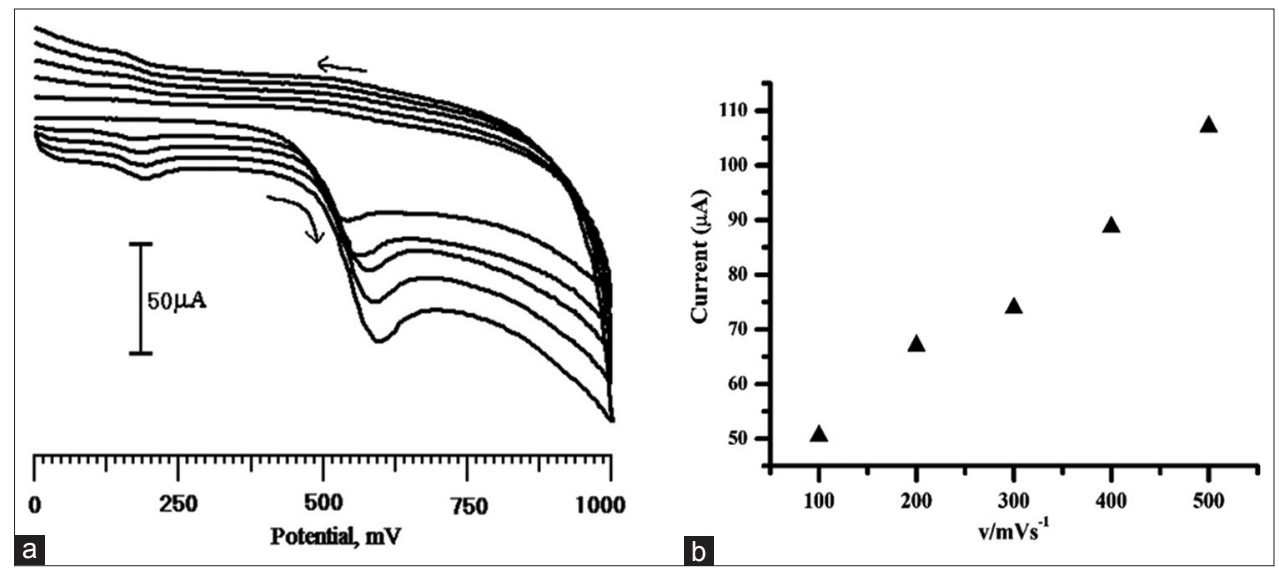

Fig. 6: (a) Cyclic voltammograms of $1 \mathrm{mM}$ resorcinol (RS) at the SDSMCNTGMPE in pH 7 phosphate buffer solutions at various scan rates. From: 100, 200, 300, 400, and $500 \mathrm{mV} / \mathrm{s}$. (b) Plot of the peak current of RS as a function of the scan rate

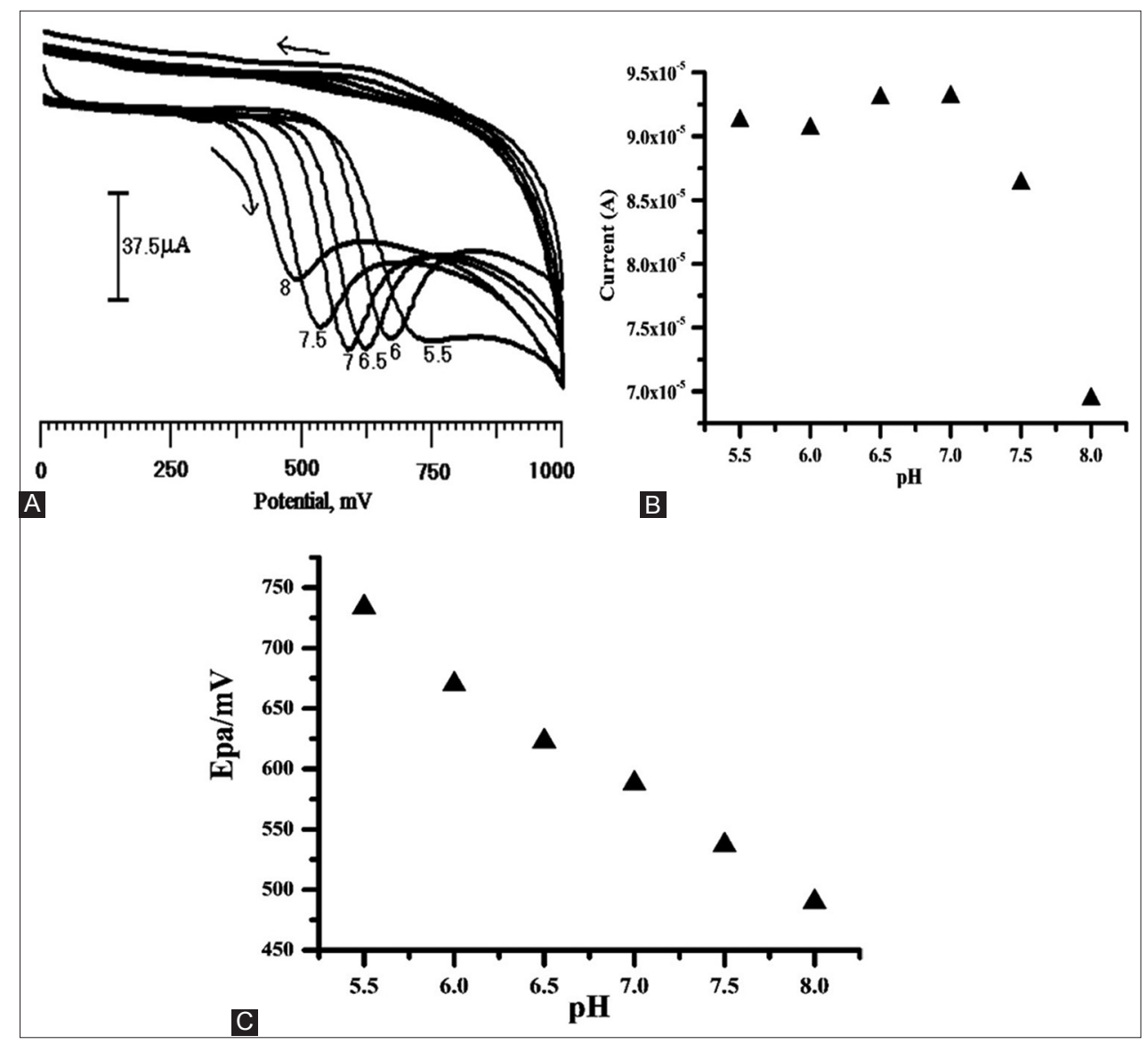

Fig. 7: (A) Cyclic voltammograms obtained at the SDSMCNTGMPE in 0.2 M phosphate buffer solutions in pH values, (a) 5.5 (b) 6 (c) 6.5 (d) 7 (e) 7.5 (f) 8 containing 1 mM resorcinol (RS), (B) plot of anodic peak current versus pH (5.5-8.0) of 1 mm RS at the SDSMCNTGMPE, (C) plot of Epa versus pH for RS

Determination of RS in commercial sample

To verify the reliability of the method for analysis of RS in commercial sample, this SDSMCNTGMPE was applied to determine RS in RS injection, with required amounts of the diluted commercial sample being shifted into the cell for the determination using $\mathrm{CV}$.

The injections of RS were analyzed by the standard addition method. The injection sample was used after suitable dilution; it contains $4 \mathrm{~g} / 100 \mathrm{~mL}$ RS. The mixtures were diluted to achieve different known standard 100,200 , and $300 \mu \mathrm{M}$ concentrations of RS. The sample solutions were analyzed by CV using the SDSMCNTGMPE.
Each experiment was repeated out at least 5 times and the results are presented in Table 2. The recoveries ranged from $98.5 \%$ to $101.1 \%$. The results are receivable, showing that our recommended method could be efficiently used for the determination of RS in commercial samples.

\section{CONCLUSIONS}

In this paperwork, we have prepared and characterized a SDSMCNTGMPE. SDSMCNTGMPE surface was probed by VPSEM, DPV, and $\mathrm{CV}$ techniques. The high sensitivity and low detection limit together with the ease of preparation and good repeatability and better stability 


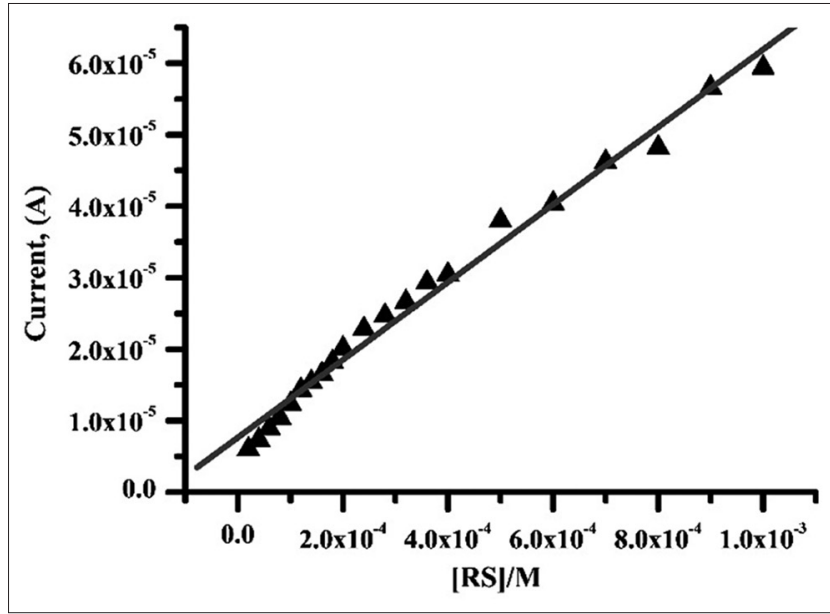

Fig. 8: Calibration plot for the determination of resorcinol at the SDSMCNTGMPE in $\mathrm{pH} 7$ phosphate buffer solutions with the scan rate $100 \mathrm{mV} / \mathrm{s}$

Table 1: The comparison of SDSMCNTGMPE with some modified electrodes for the determination of RS

\begin{tabular}{llll}
\hline Electrode & $\begin{array}{l}\text { Detection } \\
\text { limit (M) }\end{array}$ & Method & References \\
\hline $\begin{array}{l}\text { Graphene-chitosan/ } \\
\text { GCE }\end{array}$ & $7.5 \times 10^{-7}$ & DPV & {$[35]$} \\
MWNTs/ & $6 \times 10^{-7}$ & Amperometric & {$[36]$} \\
multielectrode array & & & \\
Graphene doped CILE & $4 \times 10^{-7}$ & DPV & {$[3]$} \\
MWNTs/GCE & $4.9 \times 10^{-7}$ & SWV & {$[4]$} \\
SDSMCNTGMPE & $5.8 \times 10^{-6}$ & CV & This work \\
\hline
\end{tabular}

RS: Resorcinol, CILE: Carbon ionic liquid electrode, GCE: Glassy carbon electrode, MWNTs: Multi-walled carbon nanotubes, DPV: Differential voltammetry, SWV: Square wave voltammetry, CV: Cyclic voltammetry

Table 2: Determination of $\mathrm{RS}$ in injections $(n=5)$

\begin{tabular}{llll}
\hline Sample & RS $(\boldsymbol{\mu M})$ & Found $(\boldsymbol{\mu M})$ & Recovery $(\%)$ \\
\hline 1 & 100 & 98.5 & 98.5 \\
2 & 200 & 198.8 & 99.4 \\
3 & 300 & 303.3 & 101.1 \\
\hline
\end{tabular}

RS: Resorcinol

of the SDSMCNTGMPE are the applications of the proposed electrode. Table shows some parameters such as detection limit and linear range for analysis of RS by the proposed electrode in contrasting with some other electrochemical procedure.

\section{ACKNOWLEDGMENTS}

We gratefully acknowledge the financial support (seed money for young scientist scheme) from the VGST, Bengaluru, under Research Project. No. VGST/SMYSR/2014-15/GRD-395/2015-16, April 30, 2015.

\section{REFERENCES}

1. Xie T, Liu Q, Shi Y, Liu Q. Simultaneous determination of positional isomers of benzenediols by capillary zone electrophoresis with square wave amperometric detection. J Chromatogr A 2006;1109(2):317-21.

2. Ahammad AJ, Sarker S, Rahman MA, Lee JJ. Simultaneous determination of hydroquinone and catechol at an activated glassy carbon electrode. Electroanalysis 2010;22(6):694-700.

3. Hossain MU, Rahman MT, Ehsan MQ. Simultaneous detection and estimation of catechol, hydroquinone, and resorcinol in binary and ternary mixtures using electrochemical techniques. Int J Anal Chem 2015;2015:862979. http://dx.doi.org/10.1155/2015/862979.
4. Ghoreishi SM, Behpour M, Hajisadeghian E, Golestaneh M. Voltammetric determination of resorcinol on the surface of a glassy carbon electrode modified with multi-walled carbon nanotube. Arab J Chem 2016;9 Suppl 2:S1563-8

5. Du J, Li Y, Lu J. Flow injection chemiluminescence determination of polyhydroxy phenols using luminol-ferricyanide/ferrocyanide system. Talanta 2001;55(6):1055-8.

6. Yang L, Wang Z, Xu L. Simultaneous determination of phenols (bibenzyl, phenanthrene, and fluorenone) in Dendrobium species by high-performance liquid chromatography with diode array detection. J Chromatogr A 2006;1104(1-2):230-7.

7. Pistonesi MF, Di Nezio MS, Centurión ME, Palomeque ME, Lista AG, Fernández Band BS. Determination of phenol, resorcinol and hydroquinone in air samples by synchronous fluorescence using partial least-squares (PLS). Talanta 2006;69(5):1265-8.

8. Zargar B, Hatamie A. Colorimetric determination of resorcinol based on localized surface plasm on resonance of silver nanoparticles. Analyst 2012;21(22):5334-38.

9. Khalaf KD, Hasan BA, Morales-Rubio A, de la Guardia M. Spectrophotometric determination of phenol and resorcinol by reaction with p-aminophenol. Talanta 1994;41(4):547-56.

10. Manjunatha JG, Deraman M, Basri NH, Nor NS, Talib IA, Ataollahi N. Sodium dodecyl sulfate modified carbon nanotubes paste electrode as a novel sensor for the simultaneous determination of dopamine, ascorbic acid, and uric acid. C R Chimie 2014;17:465-76.

11. Manjunatha JG, Swamy BE, Mamatha GP, Gilbert O, Shreenivas MT, Sherigara BS. Electrochemical studies of clozapine drug using carbon nanotube-SDS modified carbon paste electrode: A cyclic voltammetry study. Pharma Chemica 2011;3(2):236-49.

12. Manjunatha JG, Deraman M, Basri NH. Electrocatalytic detection of dopamine and uric acid at poly (basic blue b) modified carbon nanotube paste electrode. Asian J Pharm Clin Res 2015;8(5):48-53.

13. Manjunatha JG. Poly (Nigrosine) modified electrochemical sensor for the determination of dopamine and uric acid: A cyclic voltammetric study. Int J Chem Tech Res 2016;9(2):136-46.

14. Manjunatha JG, Deraman M, Basri NH, Talib IA. Selective detection of dopamine in the presence of uric acid using polymerized phthalo blue film modified carbon paste electrode. Adv Mat Res 2014;895:447-51.

15. Manjunatha JG, Deraman M, Basri NH, Talib IA. Fabrication of poly (solid red A) modified carbon nanotube paste electrode and its application for simultaneous determination of epinephrine, uric acid and ascorbic acid. Arab J Chem 2014. DOI: dx.doi.org/10.1016/j. arabjc.2014.10.009.

16. Kutluay A, Aslanoglu M. An electrochemical sensor prepared by sonochemical one-pot synthesis of multi-walled carbon nanotubesupported cobalt nanoparticles for the simultaneous determination of paracetamol and dopamine. Anal Chim Acta 2014;839:59-66.

17. Stoller MD, Park S, Zhu Y, An J, Ruoff RS. Graphene-based ultracapacitors. Nano Lett 2008;8(10):3498-502.

18. Manjunatha JG, Swamy BE, Deraman M, Mamatha GP. Simultaneous determination of ascorbic acid, dopamine and uric acid at poly (aniline blue) modified carbon paste electrode: A cyclic voltammetric study. Int J Pharm Pharm Sci 2013;5 Suppl 2:355-61.

19. Vidya DS, Prasad MS, Priya MV, Roja K, Sreedhar NY. Volta metric determination of desloratadine in pharmaceutical and human urine samples using glassy carbon electrode. Int J Pharm Pharm Sci 2014;6(10):119-22.

20. Manjunatha JG. A novel poly (glycine) biosensor towards the detection of indigo carmine: A voltammetric study. J Food Drug Analysis 2017. DOI: dx.doi.org/10.1016/j.jfda.2017.05.002.

21. Nithya G, Kanakam CC, Sudha R. Cyclic voltammetric studies for different substituted benzils. Asian J Pharm Clin Res 2016;9(3):82-4.

22. Farma R, Deraman M, Awitdrus A, Talib IA, Omar R, Manjunatha JG, et al. Physical and Electrochemical Properties of super capacitor electrodes derived from carbon nanotube and biomass carbon. Int J Electrochem Sci 2013;8:257-73.

23. Georgakilas V, Otyepka M, Bourlinos AB, Chandra V, Kim N, Kemp KC. Functionalization of grapheme: Covalent and non-covalent approaches, derivatives and applications. Chem Rev 2012;112(11):6156-214.

24. Yen MY, Hsiao MC, Liao SH, Liu PI, Tsai HM, Ma CC. Preparation of graphene/multi-walled carbon nanotube hybrid and its use as photo anodes of dye-sensitized solar cells. Carbon 2011;49(11):3597-606

25. Xu C, Wang X, Zhu J. Graphene-metal particle nano composites. J Phys Chem C 2008;112:19841-845.

26. Wang X, Tabakman SM, Dai H. Atomic layer deposition of metal oxides on pristine and functionalized graphene. J Am Chem Soc 2008;130:8152-153. 
27. Moghaddam AB, Mohammadi A, Fathabadi M. Application of carbon nanotube-graphite mixture for the determination of diclofenac sodium in pharmaceutical and biological samples. Pharmaceut Anal Acta 2012;3(5):1-6.

28. Alarcon-Ángeles G, Corona-Avendano S, Palomar-Pardave M, Rojas-Hernandez A, Romero-Romo M, Ramírez-Silva MT. Selective electrochemical determination of dopamine in the presence of ascorbic acid using sodium dodecyl sulfate micelles as masking agent. Electrochim Acta 2008;53(6):3013-20.

29. Corona-Avendano S, Alarcon-Angeles G, Romero-Romo M, Cuan A, Ramirez-Silva MT, Hernandez-Martinez L, et al. Influence of CTAB on the electrochemical behavior of dopamine and on its analytic determination in the presence of ascorbic acid. J Appl Electrochem 2010;40(2):463-74.

30. Colin-Orozco E, Ramirez-Silva MT, Corona-Avendano S, RomeroRomo M, Palomar-Pardave M. Electrochemical quantification of dopamine in the presence of ascorbic acid and uric acid using a simple carbon paste electrode modified with SDS micelles at $\mathrm{pH}$ 7. Electrochim Acta 2012;85:307-13.

31. Corona-Avendano S, Alarcon-Ángeles G, Ramírez-Silva MT,
Rosquete-Pina G, Romero-Romo M, Palomar-Pardave M. On the electrochemistry of dopamine in aqueous solution. Part I: The role of [SDS] on the voltammetric behavior of dopamine on a carbon paste electrode. J Electroanal Chem 2007;609(1):17-26.

32. Wang H, Qiao X, Chen J, Ding S. Preparation of silver nanoparticles by chemical reduction method. Colloids Surf A 2005;256(2-3):111-15.

33. Bard AJ, Faulkner LR. Electrochemical Methods: Fundamental and Application. New York: Wiley; 2000.

34. Gosser DK. Cyclic Voltammetry Simulation and Analysis of Reaction Mechanisms. Weinheim: VCH; 1993.

35. Yin H, Zhang Q, Zhou Y, Ma Q, Liu T, Zhu L, et al. Electrochemical behaviour of catechol, resorcinol and hydroquinone at graphemechitosan composite film modified glassy carbon electrode and their simultaneous determination in water samples. Electrochim Acta 2011;56(6):2748-753.

36. Zhang D, Peng Y, Qi H, Gao Q, Zhang C. Application of multielectrode array modified with carbon nanotubes to simultaneous amperometric determination of dihydroxybenzene isomers. Sens Actuators B 2009;136(1):113-21. 